\title{
QUALIDADE DO GASTO PÚBLICO EM EDUCAÇÃO E SAÚDE: UMA ANÁLISE MICRORREGIONAL EM GOIÁS
}

\author{
QUALITY OF PUBLIC COSTS IN EDUCATION AND HEALTH: A \\ MICROREGIONAL ANALYSIS IN GOIAS STATE
}

\author{
Ricardo Neves Borges ${ }^{1}$ \\ Paulo Cesar Bontempo ${ }^{2}$ \\ Alcido Elenor Wander ${ }^{3}$ \\ Estela Najberg ${ }^{4}$
}

\begin{abstract}
RESUMO
Este trabalho tem como objetivo avaliar e comparar a qualidade do gasto público em educação e saúde em todas as microrregiões do estado de Goiás. Para tanto, foram analisados dados secundários relativos a vários indicadores sociais, os quais foram comparados com as despesas incorridas com educação e saúde nas diversas microrregiões de Goiás, por meio da construção de um Índice de Qualidade do Gasto Público (IQGP). Na avaliação da qualidade dos gastos com educação, os resultados por microrregião foram avaliados por meio de uma ponderação de cinco indicadores. Para a avaliação dos gastos com saúde, os resultados por microrregião foram medidos pela ponderação de seis indicadores. A partir de então, foi possível concluir que as microrregiões que apresentam uma maior despesa per capita não são as que têm os melhores desempenhos no que diz respeito à qualidade dos gastos.
\end{abstract}

Palavras-chave: Índice de Qualidade do Gasto Público; Microrregião; Educação; Saúde.

\begin{abstract}
This work has as goal evaluates and compares the quality of public costs in education and health in all the micro-regions of the State of Goias. For both, it was analyzed secondary data relative to several social indicators. These indicators were compared with the expenses incurred with education and health in the several micro-regions of Goias, through the construction of a Quality of Public Cost Index (IQGP). In the quality evaluation of costs with education, the results for micro-region were measured through the weighting of five indicators. For the evaluation of health costs, the results for micro-region were measured through the weighting of six indicators. We can conclude that the microregions that presented a higher expense per capita are not the ones that present better performances regarding cost quality.
\end{abstract}

Keywords: Quality of Public Cost Index; Micro-region; Education; Health.

\footnotetext{
${ }^{1}$ Mestre em Desenvolvimento Regional pela Faculdade ALFA. Docente na Universidade de Rio Verde (UniRV) e Faculdade de Chapadão do Sul (Fachasul).

${ }^{2}$ Doutor em Administração de Empresas pela Universidade de São Paulo (USP). Professor titular e pesquisador do Mestrado em Desenvolvimento Regional das Faculdades Alves Faria.

${ }^{3}$ Graduado em Agronomia pela Universidade de Kassel (1996), mestre em Ciências Agrárias dos Trópicos e Subtrópicos pela Georg August Universität Göttingen, Alemanha (1998), e doutor em Ciências Agrárias pela Georg August Universität Göttingen (2002). Atualmente é professor titular da Faculdade Alfa, pesquisador da Universidade Federal de Goiás e pesquisador da Empresa Brasileira de Pesquisa Agropecuária.

${ }^{4}$ Doutora em Administração pela EAESP - FGV e professora da Universidade Federal de Goiás.
} 


\section{Introdução}

Considerando-se os protestos realizados em todo o Brasil em 2013, o debate e a análise crítica sobre a qualidade dos gastos públicos adquirem importância, dada a necessidade de esses gastos serem dispensados da melhor forma possível. Conforme aponta Mendes (2006, p. 33), uma melhor gestão do gasto público é importante para que um país possa alcançar taxas mais elevadas de crescimento econômico, reduzir a desigualdade social, criar mais oportunidades de emprego e diminuir os índices de violência.

Tendo em vista a relevância da educação e saúde para o desenvolvimento regional, este artigo tem como objetivo mensurar a qualidade dos gastos realizados em educação e saúde em todas as microrregiões do estado de Goiás. De acordo com dados do Instituto Brasileiro de Geografia e Estatística (IBGE), o estado de Goiás possui 6.003.788 habitantes, ocupando 3,99\% do território nacional. Essa área comporta 246 municípios, que podem ser agrupados em 18 microrregiões. Conforme demonstrado na Tabela 1, existem discrepâncias entre as microrregiões do estado de Goiás em relação à distribuição populacional.

Tabela 1 - População total, percentual da população para o estado, área total $\left(\mathrm{km}^{2}\right)$ e densidade demográfica $\left(\mathrm{hab} / \mathrm{km}^{2}\right)$ das microrregiões do estado de Goiás, em 2009

\begin{tabular}{|c|c|c|c|c|}
\hline Microrregião & $\begin{array}{l}\text { Número de } \\
\text { habitantes }\end{array}$ & $\begin{array}{c}\% \text { do } \\
\text { estado }\end{array}$ & $\begin{array}{c}\text { Área total } \\
\left(\mathbf{k m}^{2}\right)\end{array}$ & $\begin{array}{c}\text { Densidade } \\
\text { demográfica } \\
\left(\mathbf{h a b} . / \mathbf{k m}^{2}\right)\end{array}$ \\
\hline Anápolis & 536.696 & 9,06 & $8.311,93$ & 64,57 \\
\hline Anicuns & 103.863 & 1,75 & $5.464,61$ & 19,01 \\
\hline Aragarças & 55.305 & 0,93 & $11.053,85$ & 5,00 \\
\hline Catalão & 141.552 & 2,39 & $15.206,84$ & 9,31 \\
\hline Ceres & 223.970 & 3,78 & $13.163,01$ & 17,02 \\
\hline Chapada dos Veadeiros & 63.416 & 1,07 & $21.337,54$ & 2,97 \\
\hline Entorno de Brasília & 1.023 .514 & 17,27 & $38.131,58$ & 26,84 \\
\hline Goiânia & 2.128 .243 & 35,91 & $6.824,79$ & 311,84 \\
\hline Iporá & 59.909 & 1,01 & $7.072,35$ & 8,47 \\
\hline Meia Ponte & 355.781 & 6,00 & $21.165,56$ & 16,81 \\
\hline Pires do Rio & 94.450 & 1,59 & $9.418,37$ & 10,03 \\
\hline Porangatu & 226.752 & 3,83 & $35.171,85$ & 6,45 \\
\hline Quirinópolis & 98.723 & 1,67 & $16.068,10$ & 6,14 \\
\hline Rio Vermelho & 87.875 & 1,48 & $20.205,98$ & 4,35 \\
\hline São Miguel do Araguaia & 79.822 & 1,35 & $24.381,37$ & 3,27 \\
\hline Sudoeste de Goiás & 424.683 & 7,17 & $56.111,53$ & 7,57 \\
\hline Vale do Rio dos Bois & 112.478 & 1,90 & $13.608,60$ & 8,27 \\
\hline Vão do Paranã & 109.268 & 1,84 & $17.388,82$ & 6,28 \\
\hline
\end{tabular}

Fonte: Superintendência de Pesquisa e Informação (SEPIN), adaptado pelos autores.

A microrregião (MRG) de Goiânia é a que apresenta maior número de habitantes, compreendendo 35,91\% da população do Estado, enquanto que na MRG de Aragarças está o menor número, apenas 0,93\% da população total do Estado. Observa-se que a concentração da população na MRG de Goiânia é cinco vezes maior que a da MRG de Anápolis, que por sua vez apresenta a segunda maior densidade demográfica. A densidade demográfica da MRG de Goiânia é 105 vezes maior que a da MRG da Chapada dos Veadeiros, cuja densidade demográfica é a menor do estado. 


\section{Referencial teórico}

\subsection{O gasto público}

De acordo com Riani (2002, p. 80), o gasto público é a escolha que os governantes fazem para a aplicação dos recursos públicos em diversos serviços para a sociedade. Os gastos públicos representam o custo da quantidade e da qualidade dos serviços oferecidos pelos governos, sendo classificados por ação, programa, finalidade e natureza, podendo ser de custeio, investimentos, transferências e inversões financeiras (REZENDE, 2001).

Com base na Lei $n^{\circ} 4.320 / 64$, os gastos dos governos são divididos em duas categorias básicas: as despesas correntes e as despesas de capital.

Os gastos públicos, no entanto, não representam necessariamente um aumento de serviços prestados pelo governo. Giambiagi e Além (2008, p. 33) afirmam que o governo não é uma abstração, e sim uma entidade que coleta recursos que retornam em forma de benefícios para o contribuinte. Após essa coleta de recursos, o governo passa a assumir funções - das quais as mais importantes são a "Saúde, Educação, Defesa Nacional, Policiamento, Regulação, Justiça e Assistencialismo" - que, do contrário, ninguém iria realizar, pois se trata de ofertas de bens públicos.

Na visão de Giambiagi e Além (2008), a iniciativa privada assume em determinados momentos alguns desses gastos, tais como a Saúde e a Educação. No entanto, os autores concluem que, além de uma parte importante da população não ter recursos para pagar por esses serviços de forma privada, é razoável considerar que o Estado tem o dever de colocar à disposição da população esse tipo de serviço, mesmo que, em alguns casos, pessoas em melhores condições optem por fazer uso dos serviços particulares.

Para Arvate e Biderman (2006), um estado austero surge quando os gastos são voltados prioritariamente às áreas onde a ação do setor público é mais necessária.

Um aspecto a se ressaltar quanto à eficácia no gasto público é a implementação e aperfeiçoamento à Lei de Responsabilidade Fiscal (LRF), que estabelece diversos métodos e práticas voltadas para o equilíbrio e a transparência fiscal.

De acordo com Giambiagi e Além (2008, p. 35), ao longo do século XX os gastos públicos aumentaram significativamente devido, principalmente, a tudo que demandou as duas grandes guerras mundiais. Para que acontecessem, foram necessários muitos gastos militares. Os dois conflitos foram historicamente um dos fatores determinantes para a expansão do gasto público no mundo. Como o governo tem atualmente um poder maior na economia do que tinha em meados do século XX, os autores (p. 36) apontam outros fatores importantes para o crescimento do gasto público: primeiramente os fatores demográficos associados ao envelhecimento progressivo da população, pois "à medida que uma proporção maior da população se torna idosa, crescem os gastos totais com saúde, assim como as despesas previdenciárias", outro fenômeno importante foi a urbanização, já que, "entre 1950 e 1980, o percentual da população brasileira urbana passou de $36 \%$ para $68 \%$ da população total".

Essa urbanização resultou em significativo aumento do gasto público, pois na época em que a população era predominantemente rural, a sobrevivência estava ligada à simples agricultura de subsistência. Por não haver grandes aglomerações populacionais nesse período, virtualmente inexistia o conceito de "serviço público". Por outro lado, quando houve a 
migração do campo para a cidade, ampliaram-se as demandas dos serviços públicos relacionados à saúde, educação e à criação de uma infraestrutura de transportes coletivos.

Outro fator que Giambiagi e Além (2008, p. 36) apresentam para explicar o aumento da relação do gasto público em relação ao PIB é o crescimento do PIB per capita. Nesse caso, o efeito da renda per capita sobre a demanda por serviços públicos está estritamente ligado à urbanização, pois quando as sociedades se beneficiam com uma elevação no nível de renda, tendem a ter maior grau de escolaridade, e por sua vez exigem serviços públicos melhores.

O Gráfico 1 apresenta a evolução do PIB no Brasil e dos gastos da União no período compreendido entre 1980 a 2006.

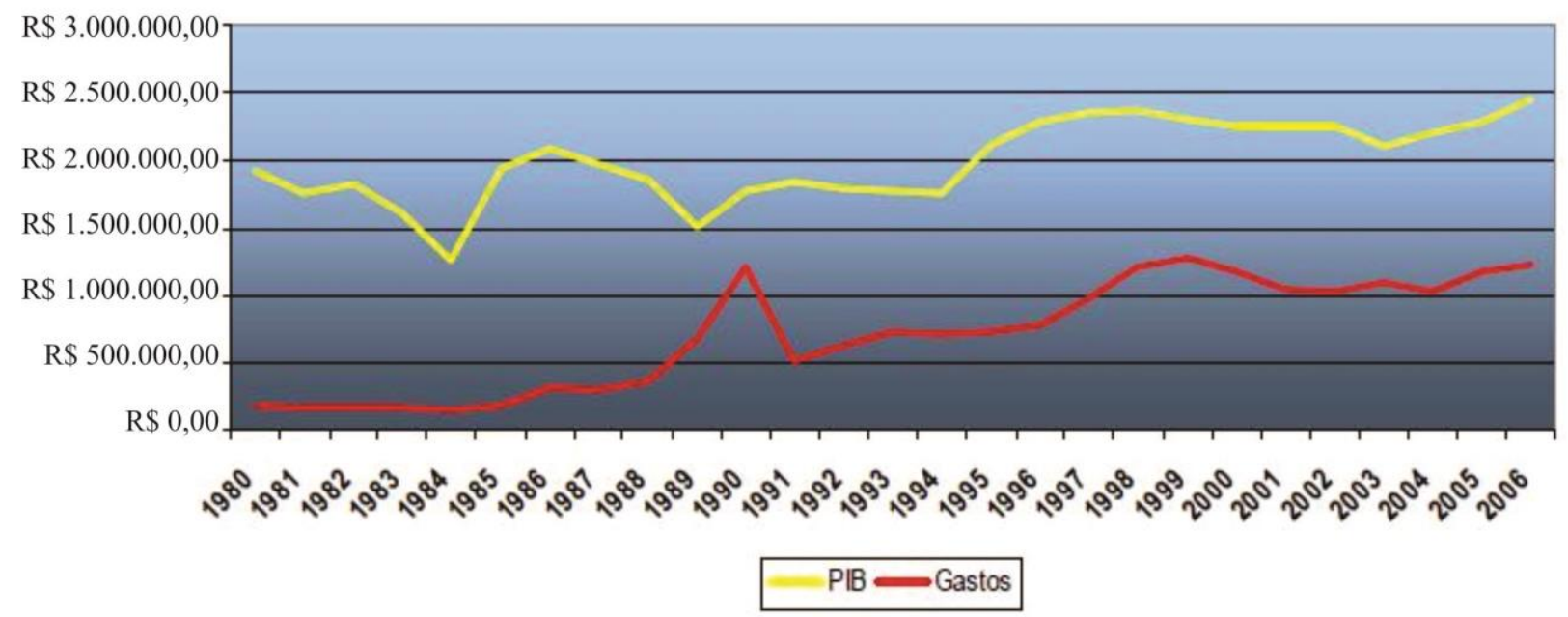

Gráfico 1 - Brasil: Evolução do PIB e dos gastos da União (1980-2006)

Fonte: Amarante e Moreira (2008, p. 4).

Conforme concluem Amarante e Moreira (2008, p. 7), a "experiência brasileira mostra que, no período de 1980 a 2006, o comportamento dos gastos governamentais apresentou uma trajetória ascendente e uma participação cada vez maior no PIB.”

\subsection{Indicadores sociais}

De acordo com Jannuzzi (2009, p. 15), um indicador social, em geral uma medida quantitativa, é utilizado para quantificar ou operacionalizar um conceito social abstrato, de interesse teórico programático. Os indicadores sociais informam algo sobre um aspecto da realidade social ou sobre mudanças que estão se processando.

Para Ferreira (2007), foi a partir de meados dos anos 1960 que o termo "indicador social" ficou consolidado, quando começou a ser utilizado como instrumento de avaliação e monitoramento de impactos de programas e políticas sociais na sociedade e como forma de observação de transformações sociais.

Ferreira (2007, p. 38) também aponta que "o indicador social é um instrumento operacional para monitoramento da realidade social, para fins de formulação e reformulação de políticas públicas." O autor enfatiza que "o conceito de indicadores sociais não deve estar 
vinculado a uma perspectiva quantitativa que limite a pesquisa sociológica apenas ao que é mensurável, mas sim ao que é relevante".

Desse modo, os indicadores sociais se prestam a subsidiar as atividades de planejamento público e formulação de políticas sociais nas diferentes esferas de governo, possibilitando o monitoramento das condições de vida e bem-estar da população e permitindo melhor aprofundamento da investigação acadêmica sobre a mudança social e sobre os determinantes dos diferentes fenômenos (JANNUZZI, 2009).

O indicador social, apesar de ser uma medida quantitativa, permite também uma análise qualitativa de um determinado processo, mas que só poderá ser entendido em sua totalidade se os dados indicativos forem analisados de modo a evidenciar a conjuntura em que se desenvolveram e quais aspectos estavam envolvidos, ou seja, "através das questões que estão por detrás daquele número" (FERREIRA, 2007, p. 40).

Jannuzzi (2009) apresenta uma distinção entre os indicadores sociais e as estatísticas públicas, levantadas nos censos demográficos, pesquisas amostrais ou coletadas nos registros administrativos de ministérios, secretarias de Estado e prefeituras.

As estatísticas públicas, de acordo com Jannuzzi (2009), são dados sociais em sua forma bruta, não inteiramente contextualizados em uma teoria social, portanto apenas parcialmente próprias para uso na interpretação empírica da realidade. Como exemplo disso, tem-se os eventos vitais, como óbitos e nascimentos, ou dados administrativos provenientes do censo escolar, como o número de alunos ou professores. Esses dados estão ainda em um estágio preliminar (bruto ou intermediário) para utilização efetiva, porém são úteis para a construção de indicadores que permitam uma apreciação mais contextualizada e comparativa (no tempo e no espaço) da realidade social, como taxas de natalidade, de evasão escolar, relação aluno/professor.

No que tange aos indicadores sociais, Jannuzzi (2009) explica que podem se referir à totalidade da população ou a grupos sociodemográficos específicos, dependendo do interesse inicialmente idealizado. Tais indicadores podem ser expressos em forma de taxas, proporções, médias, índices, distribuição por classe e também por cifras absolutas.

Os indicadores também são classificados de acordo com as temáticas mais agregadas usadas na denominação dos sistemas de indicadores sociais, como os indicadores socioeconômicos, de condições de vida, de qualidade de vida, desenvolvimento humano ou indicadores ambientais (JANNUZZI, 2009).

Em alguns casos, ainda conforme Jannuzzi (2009), os indicadores podem ser classificados para mais de uma temática, conforme a prática de pesquisa. Por exemplo, a taxa de mortalidade infantil é um indicador demográfico útil para apontar as condições de atendimento à saúde ou de saneamento básico em que vivem certos segmentos da população. Outro exemplo é o tempo gasto com deslocamento para o trabalho, que pode ser visto como um indicador de infraestrutura urbana (transportes), mas também pode ser usado como indicador complementar das condições de trabalho da população ocupada ou de qualidade de vida nos grandes centros urbanos.

Dessa forma, os indicadores sociais são insumos básicos e indispensáveis em todas as fases do processo de formulação e implementação de uma política pública, sendo que em cada fase do processo de formulação das políticas sociais há necessidade de empregar indicadores específicos, cada qual trazendo elementos e subsídios distintos para o bom encaminhamento do processo. Jannuzzi (2009) sugere que cada aspecto de uma política pública, além dos métodos de alocação de recursos, deve ser avaliado por meio de indicadores adequados. 
Santagada (2007) e Jannuzzi (2009) mencionam que os indicadores sociais estão inseridos em um contexto socioeconômico amplo, além também de pertencer ao campo teórico acadêmico. Esses indicadores são úteis para possibilitar o conhecimento de diferentes sociedades e monitorar as condições de vida da população. Segundo os autores, embora a mera existência dessas informações não garanta mudanças reais na área social, é fundamental construir as condições socioeconômicas necessárias para se conquistar e fazer avançar a cidadania.

\section{Metodologia}

Este trabalho foi elaborado utilizando uma metodologia de cunho quantitativo. De acordo com Mendonça, Rocha e Nunes (2008, p. 45), essa caracterização de pesquisa "É muito utilizada em estudos descritivos que procuram descobrir e classificar a relação entre variáveis".

Os dados foram coletados em sites de diversas instituições governamentais de pesquisa e estatística.

Foram pesquisadas informações sobre os 246 municípios do estado de Goiás. No entanto, para os dados da função "educação", foram selecionados 205 municípios, uma vez que somente esses possuíam dados completos que permitiriam a realização dos cálculos. Para os dados relativos à saúde, foram selecionados somente os 224 municípios que possuíam dados suficientes para a pesquisa.

A quantificação do desempenho em educação nos municípios goianos se deu por meio de um índice, resultado da ponderação das variáveis: Taxa de Aprovação da $1^{\text {a }}$ Série, Taxa de Aprovação da $2^{a}$ Série, Taxa de Aprovação da $3^{\text {a }}$ Série, Taxa de Aprovação da $4^{a}$ Série, Taxa de Aprovação da 1 à $4^{\text {a }}$ Série, Nota da Prova Brasil em Matemática, Nota da Prova Brasil em Português, Nota Padronizada da $4^{a}$ Série, IDEB $4{ }^{a}$ Série 2009 e Indicador de Rendimento da Educação Básica.

Para o índice do desempenho da saúde nos municípios integrantes das microrregiões do estado de Goiás, foram ponderadas as seguintes variáveis: Percentual de crianças que recebem aleitamento materno exclusivo, Percentual de cobertura de consultas de pré-natal, Taxa de mortalidade infantil por diarreia, Prevalência de desnutrição, Taxa de hospitalização por pneumonia, Taxa de hospitalização por desidratação, Taxa de procedimentos clínicos atendimento.

\subsection{Método de cálculo do IQGP}

O cálculo do IQGP é uma relação entre o Índice de Bem-Estar e o Índice de Insumo (BRUNET; BERTÊ; BORGES, 2007).

$$
I Q G P=\frac{\text { Índice de Bem-Estar }}{\text { Índice de Insumo }}
$$

O Índice de Bem-Estar, de acordo com Brunet, Bertê e Borges (2007), é dado pelos indicadores socioeconômicos dos resultados de determinado município: 


$$
\text { Índice de Bem-Estar }=\frac{\left[\left(E B_{1}-M_{1}\right) / D P_{1}\right]+\left[\left(E B_{2}-M_{2}\right) / D P_{2}\right]+\cdots+\left[\left(E B_{m}-M_{m}\right) / D P_{m}\right]}{m}
$$

EBi significa o Escore Bruto de cada município, Mi e DPi são, respectivamente, a Média e o Desvio-Padrão dos indicadores socioeconômicos de todos os municípios para cada indicador selecionado; $\mathrm{m}$ é o total de indicadores socioeconômicos das funções selecionadas para o ano de 2009.

Outro índice que compõe a fórmula para o cálculo do IQGP de Brunet, Bertê e Borges (2007) é o de Insumo, composto pela fórmula:

$$
\text { Índice de Insumo }[(D T / P O P)-m d] / d p^{-1}
$$

Para o cálculo, considerar DT como a Despesa Total de cada microrregião, POP como a população total da microrregião em questão e md e dp, respectivamente, a Média e o Desvio-Padrão da despesa per capita dos municípios analisados.

Após o cálculo do Índice de Bem-Estar e do Índice de Insumo, o IQGP é obtido pela razão entre os dois índices anteriores, que representa o quanto de retorno é possível obter para cada município em função da relação ao que foi despendido pelos municípios para cada função selecionada.

De acordo com a metodologia apresentada por Borges (2010) e utilizada neste trabalho, quanto maior o Índice de Bem-Estar de uma determinada microrregião, em comparação com as demais microrregiões, maior será a pontuação dessa microrregião. $\mathrm{O}$ inverso ocorre com as despesas, ou seja, quanto maior o Índice de Insumo de determinada microrregião em comparação com as demais microrregiões, menor será sua pontuação relativa.

Após a divisão da pontuação do Índice de Bem-Estar pelo Índice de Insumo obtém-se o Índice de Qualidade do Gasto Público de acordo com a metodologia desenvolvida por Brunet, Bertê e Borges (2007) e Borges (2010).

\section{Resultados}

Conforme ilustrado no Gráfico 2, a seguir, quanto maior a proximidade de uma microrregião ao lado superior esquerdo, maior será seu IQGP. 


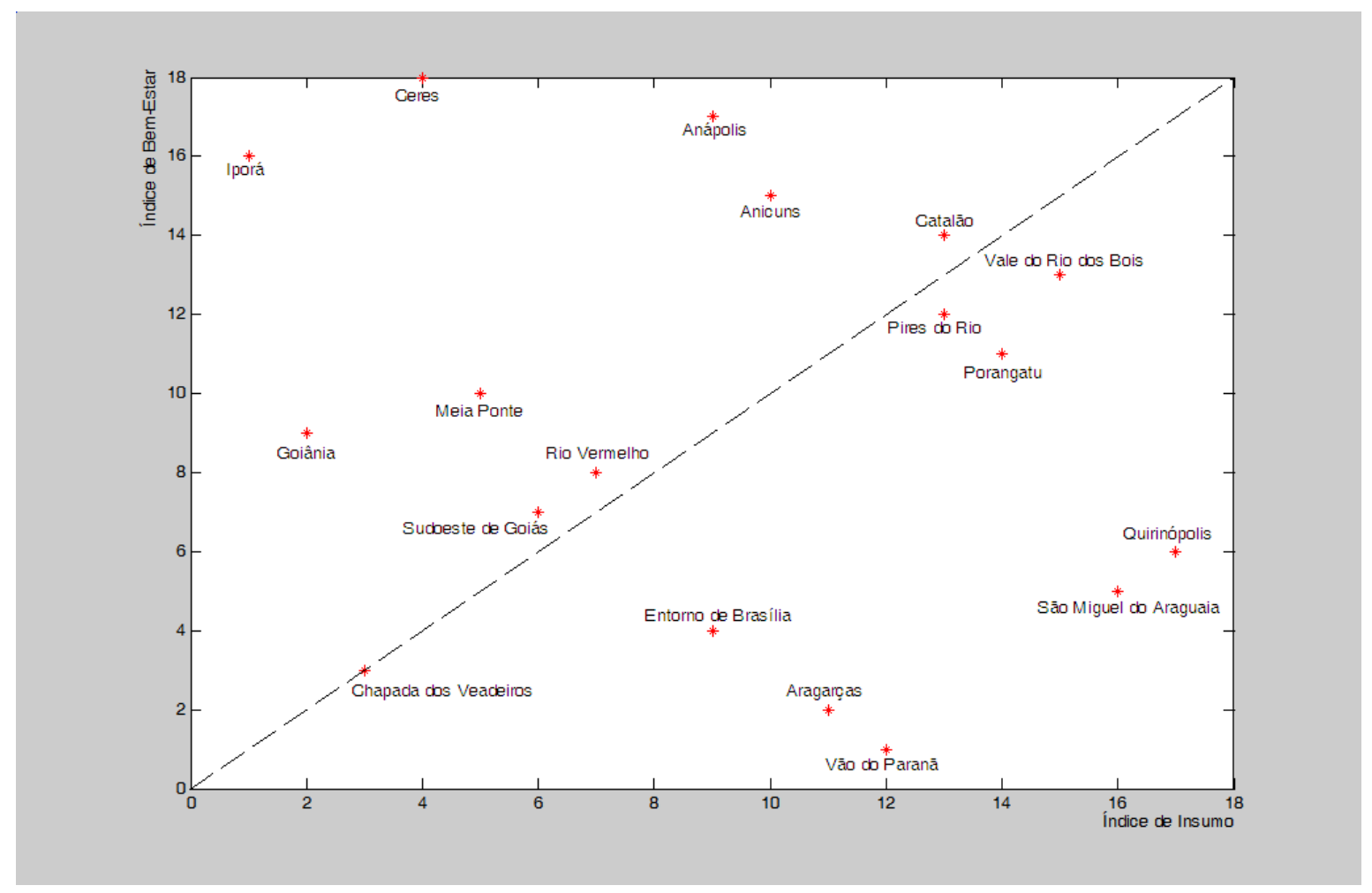

Gráfico 2 - Índice de Qualidade do Gasto Público com Educação, em 2009

Fonte: Elaborado pelos autores, com base nos dados do Portal IDEB, Finbra e TCM-GO.

Percebe-se também que a bissetriz do Gráfico 2 é o lugar geométrico em que o retorno, em termos de bem-estar social para a população residente, é igual ao valor gasto. Portanto, ao longo da bissetriz, o IQGP sempre será igual a um.

Os resultados do IQGP-Educação foram tabulados considerando os indicadores sociais e gastos de 2009, conforme apresentado no Gráfico 2. As microrregiões mais bem classificadas são as de Iporá, Goiânia e Ceres.

A partir dos resultados apresentados na Tabela 2, constata-se que a MRG Quirinópolis, apesar de ter sido a que mais investiu no ano de 2009, não teve retornos em níveis de bemestar, uma vez que essa MRG ocupa apenas a $14^{\circ}$ posição.

Por outro lado, a MRG Iporá apresentou, relativamente às demais MRGs, o menor investimento em educação em 2009, e apesar disso foi a que teve maiores retornos em níveis de bem-estar. Pode-se concluir, portanto, que dispender maiores gastos não está relacionado a ter melhores resultados. 
Tabela 2 - Índice de Qualidade do Gasto Público em Educação nas microrregiões de Goiás, em 2009

\begin{tabular}{|c|c|c|c|c|c|c|}
\hline Microrregião & $\begin{array}{l}\text { Índice de } \\
\text { Bem-Estar }\end{array}$ & Pontuação & $\begin{array}{c}\text { Índice de } \\
\text { Insumo }\end{array}$ & Pontuação & $\begin{array}{c}\text { IQGP- } \\
\text { Educação }\end{array}$ & Classificação \\
\hline Anápolis & 4,440 & 17 & $-0,526$ & 9 & 1,889 & $4^{\circ}$ \\
\hline Anicuns & 3,510 & 15 & $-0,423$ & 10 & 1,500 & $5^{\circ}$ \\
\hline Aragarças & $-8,254$ & 2 & $-0,364$ & 11 & 0,182 & $16^{\circ}$ \\
\hline Catalão & 2,968 & 14 & $-0,255$ & 13 & 1,077 & $8^{\circ}$ \\
\hline Ceres & 5,082 & 18 & $-0,782$ & 4 & 4,500 & $2^{o}$ \\
\hline Chapada dos & & & & & & \\
\hline Veadeiros & $-8,038$ & 3 & $-0,823$ & 3 & 1,000 & $9^{\circ}$ \\
\hline Entorno de Brasília & $-6,388$ & 4 & $-0,522$ & 9 & 0,444 & $13^{\circ}$ \\
\hline Goiânia & $-1,043$ & 9 & $-0,856$ & 2 & 4,500 & $2^{o}$ \\
\hline Iporá & 3,943 & 16 & $-0,931$ & 1 & 16,000 & $1^{\mathrm{o}}$ \\
\hline Meia Ponte & $-0,811$ & 10 & $-0,730$ & 5 & 2,000 & $3^{\circ}$ \\
\hline Pires do Rio & 0,638 & 12 & $-0,255$ & 13 & 0,923 & $10^{\circ}$ \\
\hline Porangatu & 0,029 & 11 & $-0,129$ & 14 & 0,786 & $12^{\circ}$ \\
\hline Quirinópolis & $-2,268$ & 6 & 0,142 & 17 & 0,353 & $14^{\circ}$ \\
\hline $\begin{array}{l}\text { Rio Vermelho } \\
\text { São Miguel do }\end{array}$ & $-1,466$ & 8 & $-0,593$ & 7 & 1,143 & $7^{\circ}$ \\
\hline Araguaia & $-3,242$ & 5 & 0,068 & 16 & 0,313 & $15^{\circ}$ \\
\hline $\begin{array}{l}\text { Sudoeste de Goiás } \\
\text { Vale do Rio dos }\end{array}$ & $-2,141$ & 7 & $-0,600$ & 6 & 1,167 & $6^{\circ}$ \\
\hline Bois & 2,616 & 13 & $-0,002$ & 15 & 0,867 & $11^{\circ}$ \\
\hline Vão do Paranã & $-8,978$ & 1 & $-0,259$ & 12 & 0,083 & $17^{\circ}$ \\
\hline
\end{tabular}

Fonte: Elaborado pelos autores, com base nos dados do Portal IDEB, Finbra e TCM-GO.

Ainda com base na análise na Tabela 2, pode-se verificar que as três MRGs com maior investimento em educação - Quirinópolis, São Miguel do Araguaia e Vale do Rio dos Bois não apresentam os três melhores IQGPs em Educação. Pelo contrário, figuram a $14^{\circ}, 15^{\circ}$ e $11^{\circ}$ colocação, respectivamente.

Pode-se concluir que, de modo geral, os resultados obtidos confirmam as conclusões do trabalho original de Brunet, Bertê e Borges (2007), uma vez que as microrregiões em que se observam maiores gastos não são as que apresentam os melhores resultados relativos. Ou seja, dispender maiores gastos não garante melhor posicionamento de uma microrregião em relação às demais.

O Gráfico 3 apresenta os resultados tabulados do IQGP-Saúde, considerando os indicadores sociais e gastos em 2009. Verifica-se que as microrregiões com melhores resultados são as do Entorno de Brasília, Vão do Paranã e Pires do Rio. 


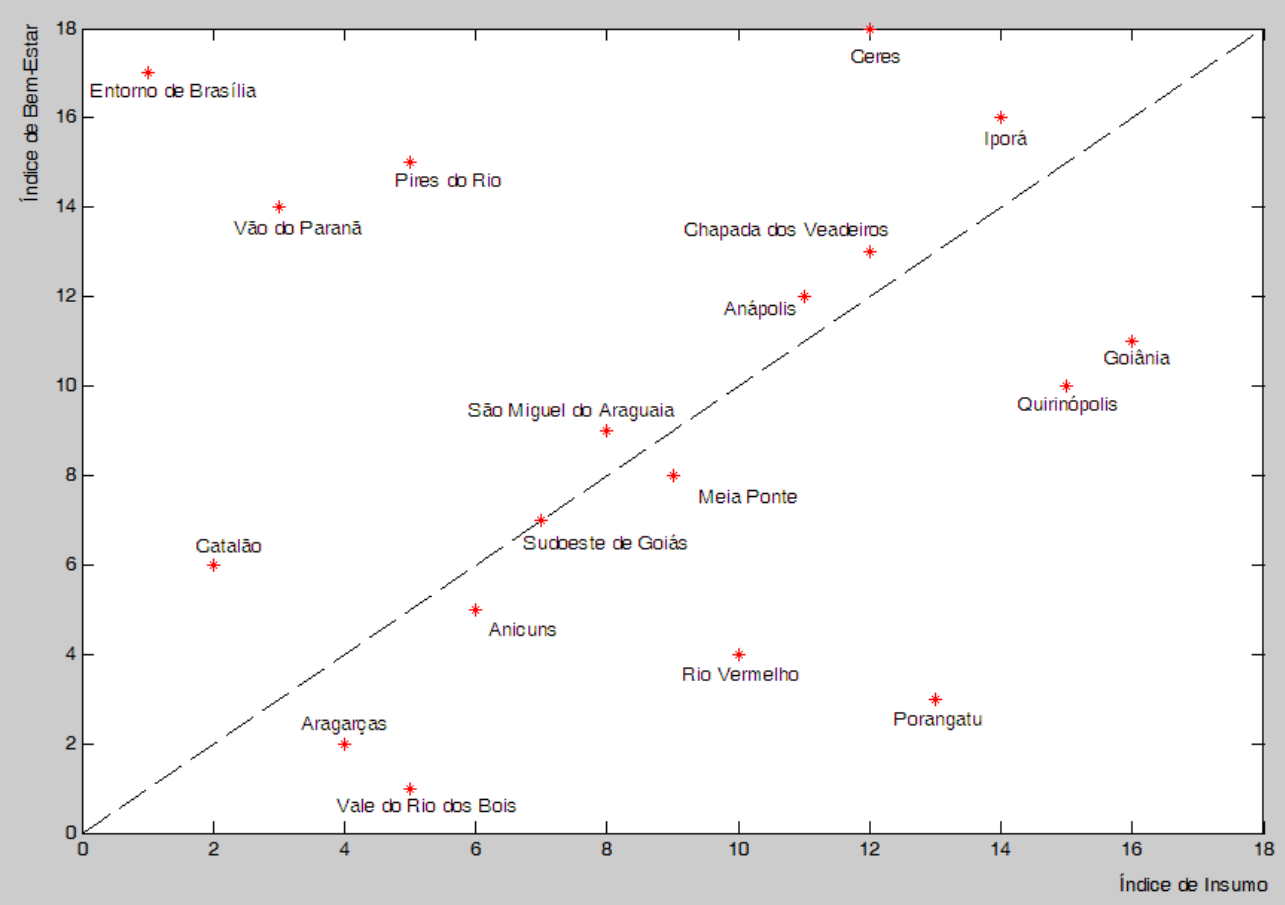

Gráfico 3 - Índice de Qualidade do Gasto Público com Saúde, em 2009

Fonte: Elaborado pelos autores, com base nos dados do Portal Datasus, Finbra e TCM-GO.

Na Tabela 3 são apresentados os gastos com Saúde em 2009. A partir dos resultados apresentados, constata-se que a MRG Entorno de Brasília foi a que mais investiu no ano de 2009, gerando maiores níveis de bem-estar, e por isso ficou em primeiro na colocação geral entre as microrregiões quanto aos investimentos em Saúde.

Observa-se que as MRGs de Quirinópolis, Iporá e Porangatu apresentaram, juntamente com a MRG Entorno de Brasília, os maiores gastos com Saúde em 2009. No entanto, essas microrregiões ocupam a $13^{\mathrm{a}}, 5^{\mathrm{a}}$ e $16^{\mathrm{a}}$ colocações na classificação geral das microrregiões, indicando que efetuar maiores gastos não está necessariamente relacionado a ter melhores resultados. 
Tabela 3 - Índice de Qualidade do Gasto Público em Saúde nas microrregiões de Goiás, em 2009

\begin{tabular}{|c|c|c|c|c|c|c|}
\hline Microrregião & $\begin{array}{c}\text { Índice de } \\
\text { Bem-Estar }\end{array}$ & Pontuação & $\begin{array}{c}\text { Índice de } \\
\text { Insumo }\end{array}$ & Pontuação & $\begin{array}{l}\text { IQGP- } \\
\text { Saúde }\end{array}$ & Classificação \\
\hline Anápolis & 0,261 & 12 & $-0,137$ & 11 & 1,091 & $7^{\circ}$ \\
\hline Anicuns & $-0,412$ & 5 & $-0,203$ & 6 & 0,833 & $11^{\circ}$ \\
\hline Aragarças & $-0,665$ & 2 & $-0,256$ & 4 & 0,500 & $14^{\circ}$ \\
\hline Catalão & $-0,403$ & 6 & $-0,429$ & 2 & 3,000 & $3^{\circ}$ \\
\hline Ceres & 0,852 & 18 & $-0,125$ & 12 & 1,500 & $4^{\circ}$ \\
\hline Chapada dos Veadeiros & 0,263 & 13 & $-0,125$ & 12 & 1,083 & $8^{\circ}$ \\
\hline Entorno de Brasília & 0,549 & 17 & $-0,430$ & 1 & 17,000 & $1^{\mathrm{o}}$ \\
\hline Goiânia & 0,208 & 11 & 0,140 & 16 & 0,688 & $12^{\circ}$ \\
\hline Iporá & 0,498 & 16 & $-0,053$ & 14 & 1,143 & $5^{\circ}$ \\
\hline Meia Ponte & $-0,321$ & 8 & $-0,166$ & 9 & 0,889 & $10^{\circ}$ \\
\hline Pires do Rio & 0,445 & 15 & $-0,231$ & 5 & 3,000 & $3^{\circ}$ \\
\hline Porangatu & $-0,663$ & 3 & $-0,123$ & 13 & 0,231 & $16^{\circ}$ \\
\hline Quirinópolis & $-0,029$ & 10 & 0,085 & 15 & 0,667 & $13^{\circ}$ \\
\hline $\begin{array}{l}\text { Rio Vermelho } \\
\text { São Miguel do }\end{array}$ & $-0,564$ & 4 & $-0,155$ & 10 & 0,400 & $15^{\circ}$ \\
\hline Araguaia & $-0,095$ & 9 & $-0,173$ & 8 & 1,125 & $6^{\circ}$ \\
\hline Sudoeste de Goiás & $-0,336$ & 7 & $-0,191$ & 7 & 1,000 & $9^{\circ}$ \\
\hline Vale do Rio dos Bois & $-0,674$ & 1 & $-0,231$ & 5 & 0,200 & $17^{\circ}$ \\
\hline Vão do Paranã & 0,298 & 14 & $-0,318$ & 3 & 4,667 & $2^{\circ}$ \\
\hline
\end{tabular}

Fonte: Elaborado pelos autores, com base nos dados do Portal Datasus, Finbra e TCM-GO.

\section{Considerações finais}

A análise dos resultados obtidos por meio da metodologia do IQGP permite concluir que, de forma geral, ter mais despesas não resulta necessariamente em melhores níveis de Bem-Estar, principalmente pelo fato de que a elevação relativa das despesas entre as microrregiões não garante um retorno proporcional em termos de qualidade dos gastos.

Podem ser levantadas várias hipóteses para se explicar a consistência dos resultados obtidos. Ressalta-se que as microrregiões mais bem classificadas e que obtêm um melhor retorno em níveis de Bem-Estar através dos indicadores sociais de resultado com um menor gasto comparativamente às demais microrregiões estão mais próximas dos centros administrativos do Estado de Goiás e da União, portanto, próximas da capital goiana e da capital federal. Conforme mais afastada a cidade estiver desses centros, por algum motivo as virtudes do "gastar bem" e da eficiência quanto ao gerir a administração pública vão se desfazendo.

Uma possível limitação do estudo se dá em virtude de que, neste trabalho, somente foram levados em consideração os gastos efetuados pelos municípios, desprezando-se os investimentos federais e estaduais. Outra possível limitação se dá em função da própria escolha das variáveis. Dada a disponibilidade de dados dos portais públicos de estatísticas e pesquisas, não foi possível levar em conta todas as variáveis possíveis da educação e saúde, podendo haver prejuízos quanto aos níveis de Bem-Estar. Assim, se pudessem ser 
consideradas todas as variáveis existentes nas funções selecionadas, os resultados poderiam ser diferentes, mas isso não pôde ser verificado por causa da indisponibilidade de todas elas. Outro fato relevante para os resultados da pesquisa é a exclusão de alguns municípios pelo fato de não haver dados completos para o cálculo do IQGP.

Como bem observa Borges (2010), vivencia-se um novo tempo da administração pública brasileira, em que os resultados da implementação de políticas públicas são quantificados pelos indicadores sociais de resultado. $\mathrm{O}$ amadurecimento da democracia no país propicia à sociedade ter acesso aos dados. Mesmo não sendo possível evitar a ineficiência do gasto em certos casos, ou o desperdício dos recursos públicos em algumas situações, a transparência das informações certamente contribui para o aperfeiçoamento do gasto público, de modo que possa prevalecer cada vez mais o interesse coletivo, e não o privado.

\section{REFERÊNCIAS}

AMARANTE, Patrícia Araújo; MOREIRA, Ivan Targino. A evolução dos gastos públicos por função e por grupo de despesas no período de 1980 a 2006. In: ENCONTRO DE INICIAÇÃO À DOCÊNCIA, 11., 2008, João Pessoa. Anais... João Pessoa: UFPB-PRG, $2008 . \quad$ Disponível em: <http://www.prac.ufpb.br/anais/xenex_xienid/xi_enid/monitoriapet/ANAIS/Area8/8CCSADE MT05-P.pdf>. Acesso em: 17 jan. 2014.

ARVATE, P. R.; BIDERMAN, C. Vantagens e desvantagens da intervenção do governo na economia. In: MENDES, M. (Org.). Gasto público eficiente: 91 propostas para o Desenvolvimento do Brasil. Rio de Janeiro: Topbooks, 2006.

BORGES, Matheus Fachin. Qualidade do Gasto Público Municipal: uma abordagem microrregional para o Estado do Rio Grande do Sul. 2010. 170 f. Dissertação (Mestrado) Faculdade de Ciências Econômicas, Universidade Federal do Rio Grande do Sul, Porto Alegre, Rio Grande do Sul, 2010.

BRUNET, Júlio Francisco Gregory; BERTÊ, Ana Maria de Aveline; BORGES, Clayton Brito. Estudo Comparativo das Despesas Públicas dos Estados Brasileiros: um índice de qualidade do gasto público. Brasília: ESAF, 2007. Disponível em: <http://www3.tesouro.fazenda.gov.br/Premio_TN/XIIPremio/qualidade/3qualidadeXIIPTN/re sumo.htm>. Acesso em: 18 jan. 2014.

FERREIRA, Aline Marques. A importância dos indicadores sociais na avaliação e monitoramento de cooperativas populares: a experiência do sistema de indicadores da incubadora tecnológica de cooperativas populares (ITCP/COPPE/UFRJ). 2007. $103 \mathrm{f}$. Monografia - Universidade Federal do Rio de Janeiro, Rio de Janeiro, 2007.

GIAMBIAGI, Fabio; ALÉM, Ana Claudia. Finanças Públicas: teoria e prática no Brasil. 3. ed. Rio de Janeiro: Campus, 2008.

JANNUZZI. Paulo de Martino. Indicadores Sociais no Brasil: conceitos, fontes de dados e aplicações. 4. ed. Campinas, SP: Alínea, 2009. 141 p. 
MENDES, Marcos. Despesas dos poderes autônomos: Legislativo, Judiciário e Ministério Público. In: MENDES, Marcos (Org.). Gasto Público Eficiente: 91 propostas para o Desenvolvimento do Brasil. Rio de Janeiro: Topbooks, 2006.

MENDONÇA, Alzino Furtado de; ROCHA, Cláudia Regina Ribeiro; NUNES, Heliane Prudente. Trabalhos Acadêmicos: planejamento, execução e avaliação. Goiânia: Faculdades Alves Faria, 2008.

REZENDE, Fernando A. Finanças públicas. 2. ed. São Paulo: Atlas, 2001.

RIANI, Flávio. Economia do Setor Público: uma abordagem introdutória. 4. ed. São Paulo: Atlas, 2002.

SANTAGADA, Salvatore. Indicadores sociais: uma primeira abordagem social e histórica. Pensamento Plural, Pelotas, v. 1, n. 1, p. 113-142, jul./dez. 2007. Disponível em: <http://periodicos.ufpel.edu.br/ojs2/index.php/pensamentoplural/article/viewFile/3764/3051>. Acesso em: 15 jan. 2014.

\section{SITES CONSULTADOS}

DATASUS - Dados do Sistema Único de Saúde. <www.datasus.gov.br >

IBGE - Instituto Brasileiro de Geografia e Estatística. <www.ibge.gov.br>

INEP - Instituto Nacional de Estudos e Pesquisa Educacionais. <www.inep.gov.br>

PORTAL IDEB - Portal do Índice de Desenvolvimento da Educação Básica. <www.portalideb.inep.gov.br>

TCM-GO - Tribunal de Contas dos Municípios. <www.tcm.go.gov.br 